\title{
Development of Cost Effective In Vitro Regeneration Protocol of Malaxis acuminata D. Don a Therapeutically Important Orchid Using Pseudobulbs as Explant Source
}

\author{
Chitta Ranjan Deb ${ }^{1} \&$ T. Arenmongla ${ }^{1}$ \\ ${ }^{1}$ Department of Botany, Nagaland University, Nagaland, India \\ Correspondence: Chitta Ranjan Deb, Department of Botany, Nagaland University, Nagaland, India. E-mail: \\ debchitta@rediffmail.com
}

Received: December 29, 2013

Accepted: March 8, 2014 Online Published: March 13, 2014

doi:10.5539/jps.v3n2p13

URL: http://dx.doi.org/10.5539/jps.v3n2p13

\begin{abstract}
This communication reports the in vitro culture of pseudobulb segments of Malaxis acuminata D. Don. and screening of some low cost substrata as alternative to agar. About 8-10 week old pseudobulb from the in vitro sourced plants were harvested and longitudinally cut into two halves and cultured. Within 5-6 week of culture, about 98 percent of pseudobulb segments responded positively and formed as many as 11 shoot buds per explants on MS medium enriched with sucrose $(3 \%, \mathrm{w} / \mathrm{v})$, casein hydrolysate $\left(100 \mathrm{mg} \mathrm{L}^{-1}\right)$ and $\alpha$-naphthalene acetic acid (NAA) $+\mathrm{N}^{6}$ benzyl adenine (BA) $(6 \mu \mathrm{M}$ each in combination). Incorporation of lower activated charcoal $(<0.3 \%)$ in the initiation medium did not promote shoot bud formation but a concentration of $0.3 \%$ $(\mathrm{w} / \mathrm{v})$ promoted healthy root formation and pigmentation of the plantlets. The shoot buds were converted into rooted plantlets and distinct pseudobulbs on medium containing sucrose (3\%), and NAA and BA ( $3 \mu \mathrm{M}$ each in combination) where as many as 18 shoot buds, protocorm-like bodies (PLBs) were developed per subculture. Among the three alternative substrata incorporated in the regeneration medium, regenerative response on 'foam disk' as substratum was competitive with agar gelled medium while regeneration on coconut coir and forest litter were underperformed. Production cost could be substantially reduced (about a fourth) by using foam as agar alternative. The transplants were maintained in a poly-shade ( $\sim 75 \%$ shade) for about 8 week before transferring to the natural habitat where about $75 \%$ of the transplants survived.
\end{abstract}

Keywords: alternative substrata, coconut coir as substratum, Malaxis acuminata, polyurethane foam as substratum, pseudobulbs culture, therapeutically important orchid

\section{Introduction}

The increasing popularity of orchids for cut flower and medicinal purpose has added new dimension to their propagation through in vitro technique (Arditti \& Ernst, 1993; Sungkumlong \& Deb, 2009; Deb \& Sungkumlong, 2010; Deb \& Pongener, 2011; Pongener \& Deb, 2011). With the advancement of plant tissue culture techniques, present focus is oriented towards the use of alternative explants for in vitro propagation of economically important plant taxa. It is particularly useful in out breeding plants like orchids, which generate a great deal of heterozygosity in the progeny and its successful application is markedly influenced by the source and physiological age of donor tissues. Resident meristems are frequently used as explants for in vitro propagation of orchids. There are numerous reports available on potentiality of using resident meristems to regenerate plants (Pack et al., 1998; Vij et al., 2000; Pareek \& Kothari, 2002; Deb \& Temjensangba, 2005; Tenjensangba \& Deb 2005; Sungkumlong \& Deb, 2009; Deb \& Pongener, 2011; Pongener \& Deb, 2011).

Since its introduction as a gelling agent in microbial cultures more than 100 years ago, agar has been extensively used in culture media (Babbar et al., 2005; Deb \& Pongener, 2011; Pongener \& Deb, 2011). In the past there were some studies on screening of some suitable substrata to replace the agar in plant tissue culture media because of doubts about its inertness, fear of over-exploitation of its sources and above all the exorbitant price of tissue culture grade agar (Arnold \& Erickson, 1984; Deb \& Pongener, 2011).

The genus Malaxis comprises about 300 species that are distributed throughout the tropical to temperate climate regions of the world (Deb \& Temjensangba, 2006), of which about 19 species were prevalent in India. Many species, including Malaxis acuminata, are used in the 'Ayurvedic' drug preparation. The dried pseudobulbs are 
important ingredient of 'Ashtavarga' drug used in preparation of 'Chyawanprash' an energetic herbal tonic to cure tuberculosis (Chauhan, 1990; Deb et al., 2009). Generally the species grows healthy in the area rich in decayed forest litter of primary forest and due to rapid loss of primary forest cover accompanied by extensive collection of rhizome for drug preparation turned the species into endangered category.

The species is an inherent slow grower in nature and unable to cope up the threat of extinction. In vitro propagation using resident meristems is a viable alternative for the rapid propagation. Current study investigated the regenerative competence of pseudobulb with a view to develop an additional micropropagation system and also use of some low cost substrata against agar to reduce the production cost.

\section{Materials}

\subsection{Explants Source and Processing of Explants}

In vitro source: About 1.0 to $1.5 \mathrm{~cm}$ size pseudobulbs from $\sim 8-10$ wk old in vitro raised plantlets were harvested and used as explants in the present study. The leaves were carefully removed from the pseudobulbs inside the laminar flow cabinet and the traces of agar were washed off with sterilized distilled water. The processed pseudobulbs was immersed in sterilized distilled water till used.

In vivo source: About $2.0 \mathrm{~cm}$ long freshly sprouted pseudobulbs ( $\sim 3-4 \mathrm{wk}$ after emergence) from poly house grown plants were used as explants source. The pseudobulbs were freed from leaves and scales and scrubbed thoroughly with the laboratory detergent (Labolene) (at 1:100, v/v ratio) before washing under running tap water and successively sterilized with different sterilizing agents like $0.25 \%(\mathrm{w} / \mathrm{v})$ mercuric chloride $(\sim 3 \mathrm{~min})$ followed by $70 \%(\mathrm{v} / \mathrm{v})$ ethanol $(20-30 \mathrm{Sec})$. The explants were subsequently repeatedly rinsed $4-5$ times with sterilized distilled water after every treatment. The sterilized pseudobulbs were immersed in sterilized distilled water till used. The pseudobulbs from both the sources were cut horizontally and vertically into two halves. A part of the pseudobulbs were also cut horizontally into uninodal segments. Each of which was subsequently used as an explants.

\subsection{Processing of Substrata}

Beside agar as gelling agent, three other types of substrata viz. Coconut coir, forest leaf litter and polyurethane foam (foam) were used as substrata/supporting materials as agar alternative for plant regeneration and mass multiplication. 'Foam' was procured from the mattress vendors and fresh coconuts were peeled from extracting coconut coir while, forest leaf litters were collected from the forest floor. All the substrata were sized according to our requirement and size of the culture vials. The three substrata were soaked with in diluted detergent (Extron, 1: 100 ratio) for about two hours and washed thoroughly followed by air dried. Substrata were then autoclaved at $1.05 \mathrm{Kg} \mathrm{cm}^{-2}$ pressure and $121{ }^{\circ} \mathrm{C}$ for one hour before putting them in the culture vials.

\section{Methods/Techniques}

\subsection{Initiation of Culture}

Pseudobulb segments from both the sources were inoculated on MS medium (Murashige \& Skoog, 1962) fortified with $3 \%(\mathrm{w} / \mathrm{v})$ sucrose, $100 \mathrm{mg} \mathrm{L}^{-1}$ casein hydrolysate $(\mathrm{CH}), 100 \mathrm{mg} \mathrm{L}^{-1}$ citric acid (as antioxidant). The medium was further fortified with two different plant growth regulators (PGRs) like $\alpha$-naphthalene acetic acid (NAA) and $\mathrm{N}^{6}$ benzyl adenine (BA) $(0-9 \mu \mathrm{M})$ singly or in combination. In another set of experiments, activated charcoal (AC) $(0-0.4 \%, w / v)$ was added in addition to other adjuncts to study its effect on the morphogenetic response. The medium was agar gelled and $p \mathrm{H}$ of the medium was adjusted to 5.6. About $15 \mathrm{ml}$ of medium was dispensed in each test tube $(25 \times 150 \mathrm{~mm}$ size $)$ and autoclaved at $1.05 \mathrm{Kg} \mathrm{cm}^{-2}$ pressure at $121{ }^{\circ} \mathrm{C}$ for $20 \mathrm{~min}$. For each treatment 20 explant segments were cultured. All the cultures were maintained at $25 \pm 2{ }^{\circ} \mathrm{C}$ temperature and under cool white fluorescent light at $40 \mu \mathrm{mol} \mathrm{m}^{-2} \mathrm{~s}^{-1}$ intensity and $12 / 12 \mathrm{~h} \mathrm{light/dark}$ photo cycle. The cultures were sub-cultured at 4-5 wk interval unless mentioned otherwise. Numbers of protocorm-like bodies (PLBs)/meristematic loci invoked was considered for calculating percentage of response. Mean values were obtained from five replicates of each treatment. Experimental design was completely randomized and data were analyzed by analysis of variance and correlation analysis with Statview (Abacus Concept; Inc, Berkeley, CA). The PLBs/shoot buds formed were maintained for another 1-2 passages at $4 \mathrm{wk}$ interval on optimum initiation condition for further differentiation.

\subsection{Regeneration of Plantlets and Culture Proliferation}

The PLBs with first set of leaflets (advanced stage PLBs) and young plantlets from the responding segments were transferred on MS medium supplemented with sucrose (3\%) and two different PGRs (NAA and BA) at a concentrations of 0-9 $\mu \mathrm{M}$ either singly or in combination. In the regeneration medium besides agar, different 
pre-processed substrata like coconut coir, foam disk and forest litter were used as supporting materials to which about $12 \mathrm{ml}$ of the prepared liquid media were used per test tube and sterilized. Cultures were maintained at full laboratory illumination as mentioned earlier. All the resultant new shoots/PLBs were separated at every subculture and maintained on optimum regeneration condition for culture proliferation.

\subsection{Hardening of Regenerates and Potting}

Regenerates with 4-5 leaves and roots were transferred to $1 / 2 \mathrm{MS}$ salt solution with sucrose (2\%) freed from all PGRs and maintained under normal laboratory condition for 7-8 wk. The primary hardened plants were transferred for secondary hardening to community potting mix (CPM) containing chopped forest litter, coco pits and sand (at 1:1 ratio) with a moss topping. The pots were maintained in the poly shade with a ca $75 \%$ of shading of light. The pots were watered twice in a week for two months before transferring to the natural habitat.

\section{Results}

\subsection{Initiation of Culture}

There was no meristematic loci invocation in the explants collected from the in vivo sources though there was initial swelling at the cut ends and cultures degenerated subsequently. While, the pseudobulb segments from in vitro source started swelling within 2-3 wk of culture initiation. Within 5-6 wk of culture initiation, formation of meristematic loci was registered from both distal and proximal region of segments. In general, the uninodal horizontal segments were least responsive in comparison to vertical segments. In the present study shoot buds/PLBs formation was achieved from distal and proximal ends as well as from the leaf scars of the pseudobulbs (Figure 1a). Of the different quality and quantity of PGRs tested in the present study, NAA and BA in singly treatments mostly supported PLBs formation and partial callus formation. But when used in combination, supported shoot bud induction. About $98 \%$ of cultured explants exhibited positive response on medium fortified with $6 \mu \mathrm{M}$ each of NAA and BA in combination where as many as 11 shoot buds/PLBs were formed after 70 days of culture initiation (Table 1 and Figure 1b).

Table 1. Effect of PGRs on morphogenetic response of pseudobulb segments of Malaxis acuminata from in vitro source

\begin{tabular}{|c|c|c|c|c|}
\hline \multicolumn{2}{|c|}{ PGRs Conc. $(\mu \mathrm{M})$} & \multirow{2}{*}{$\begin{array}{l}\% \text { response } \\
( \pm \mathrm{SE})\end{array}$} & \multirow{2}{*}{$\begin{array}{l}\text { No. of PLBs/shoot buds } \\
\text { formed per segment* }\end{array}$} & \multirow[t]{2}{*}{ Type of response } \\
\hline NAA & BA & & & \\
\hline 0 & 0 & - & - & No response \\
\hline 3 & 0 & $30 \pm 0.5^{\mathrm{e}}$ & $3 \pm 0.4^{\mathrm{d}}$ & PLBs formed from the cut ends \\
\hline 6 & 0 & $50 \pm 1.5^{\mathrm{d}}$ & $4 \pm 0.2^{\mathrm{d}}$ & PLBs and shoot buds formed from cut ends \\
\hline 9 & 0 & $50 \pm 1.0^{\mathrm{d}}$ & $2 \pm 0.5^{\mathrm{d}}$ & As above but degenerated \\
\hline 0 & 3 & $90 \pm 1.7^{\mathrm{b}}$ & $7 \pm 0.4^{\mathrm{b}}$ & $\begin{array}{l}\text { Undifferentiated shoot buds formed from leaf scar, tip and } \\
\text { base of the pseudobulb }\end{array}$ \\
\hline 0 & 6 & $90 \pm 2.0^{\mathrm{b}}$ & $6 \pm .02^{\mathrm{c}}$ & As above \\
\hline 0 & 9 & $75 \pm 1.5^{\mathrm{c}}$ & $6 \pm 0.4^{\mathrm{c}}$ & As above but degenerated subsequently \\
\hline 3 & 3 & $55 \pm 0.6^{\mathrm{d}}$ & $8 \pm 0.5^{b}$ & Shoot buds, and plantlet formed \\
\hline 6 & 3 & $45 \pm 1.5^{\mathrm{d}}$ & $5 \pm 0.2^{\mathrm{c}}$ & As above but not healthy \\
\hline 9 & 3 & $43 \pm 2.0^{\mathrm{d}}$ & $4 \pm 0.2^{\mathrm{d}}$ & As above \\
\hline 3 & 6 & $75 \pm 0.5^{\mathrm{c}}$ & $3 \pm 0.2^{\mathrm{d}}$ & $\begin{array}{l}\text { PLBs and shoot buds formed from the leaf scar and cut } \\
\text { ends but fewer in number }\end{array}$ \\
\hline 6 & 6 & $98 \pm 1.0^{\mathrm{a}}$ & $11 \pm 0.4^{\mathrm{a}}$ & $\begin{array}{l}\text { Pseudobulb segment swollen, shoot buds/PLBs formed } \\
\text { in cluster throughout the segment }\end{array}$ \\
\hline 9 & 6 & $67 \pm 1.5^{\mathrm{c}}$ & $6 \pm 0.2^{\mathrm{c}}$ & Cultures turned brown and degenerated \\
\hline 3 & 9 & $88 \pm 1.5^{b}$ & $5 \pm 0.1^{\mathrm{c}}$ & Shoot buds formed in cluster but degenerated \\
\hline 6 & 9 & $87 \pm 1.0^{\mathrm{b}}$ & $3 \pm 0.2^{\mathrm{d}}$ & As above \\
\hline 9 & 9 & $67 \pm 2.0^{\mathrm{c}}$ & $3 \pm 0.4^{\mathrm{d}}$ & As above \\
\hline
\end{tabular}


Data represents the mean of five replicates; Data scored after 70 days of culture; In the same column, figures followed by the same letter were statistically identical to the threshold of 5\%; On MS medium containing 3\% sucrose, $100 \mathrm{mg} \mathrm{L}^{-1} \mathrm{CH}$ and $100 \mathrm{mg} \mathrm{L}^{-1}$ citric acid.

Addition of $\mathrm{AC}$ in the initiation medium did not support optimum shoot buds formation in comparison to AC control treatment. Number of shoot buds/PLBs invoked on AC rich medium was lower than the AC control. On an average 8 shoot buds were formed at $0.3 \% \mathrm{AC}$ concentration whereas 11 shoot buds were formed in $\mathrm{AC}$ control medium (Figure 2). But incorporation of $\mathrm{AC}$ in the initiation medium promoted healthy root formation and as many as 4-5 roots were developed per shoot buds/plantlets which was lacking in AC control medium (Figure 1c). Besides this, AC enriched medium supported pigmentation in the plantlets.

\subsection{Regeneration of Culture and Culture Proliferation}

The shoot buds/advanced stage PLBs developed from pseudobulb segments on initiation medium were cultured on regeneration medium for plant regeneration and multiplication. In the regeneration medium apart from agar as gelling agent, another three substrata viz. foam disk, coconut coir and chopped forest litters were used. Within 6-8 wk of culture, the shoot buds started elongating and formed plantlets with well expanded leaves and roots. Different quality and quantity of PGRs marked a pronounced effect and elicit different responses in the plantlet development. Inclusion of PGRs in the regeneration medium was obligatory for successful regeneration of plantlets and culture proliferation.

Of the different concentrations of NAA and BA tested, a combined treatment of NAA and BA at $3 \mu \mathrm{M}$ each supported healthy regeneration and culture proliferation (Table 2). When compared, among the individual treatments, BA found to be superior over NAA. Cultures on NAA alone supported more rooting and fewer shoot buds formed. Besides this cultures exhibited swelling at the basal zone. Although cultures on BA enriched medium supported moderately higher number of shoot buds formation, but did not support healthy root formation. Under optimum condition about 18 shoot buds formed when medium was fortified with $3 \mu \mathrm{M}$ NAA and BA in combination (Table 2, Figure 1d).

\subsection{Effect of Low Cost Substrata and Their Cost Effectiveness}

In the present study with Malaxis acuminata, besides agar gelled medium, foam disk, coconut coir and forest leaf litters were used as substrata with differential success as agar alternative for regeneration and culture proliferation. Among the different substrata incorporated in the regeneration medium, better culture differentiation and proliferation was recorded on medium with 'foam disk' as substratum and agar gelled medium though agar gelled medium exhibited slightly better performance (Table 2). It was observed that initial response was better on agar gelled medium as cultures establishes faster on this medium compared to other substrata. However, once the cultures established themselves on alternative substrata especially on foam disk, they exhibited healthier growth and differentiation compared to agar gelled medium (Table 2, Figure $1 \mathrm{~d}, \mathrm{e}, \mathrm{f}, \mathrm{g}$ ). Under optimum conditions as many as 18 shoot buds were developed on the agar gelled medium compared to 14 shoot buds on the foam, while other plantlet parameters like plantlet height, number of leaves per plantlets were competitive. Number of shoot buds produced in the culture maintained on the coconut coir and forest litter substrata were considerably lower compared to medium with agar and foam (Table 2). Besides this, cultures maintained on these two conditions demanded prolonged period for differentiation and in many cases did not support healthy differentiation.

Coconut coir, and foam as agar alternative could be successfully used for initiation and regeneration phase. Healthier plant regeneration, culture proliferation was achieved on foam disk compare to the other alternative substrata. When estimated the cost effectiveness, it was calculated that the production cost could be reduced by about a fourth against agar gelled medium. 
Table 2. Effects of PGRs and different substrata on plantlet regeneration and mass multiplication of Malaxis acuminata

\begin{tabular}{|c|c|c|c|c|c|c|c|c|c|c|c|c|c|}
\hline \multirow{2}{*}{\multicolumn{2}{|c|}{$\begin{array}{l}\text { PGRs } \\
\text { Conc. }(\mu \mathrm{M})\end{array}$}} & \multicolumn{4}{|c|}{ Plantlet height (cm) $( \pm \mathrm{SE})$} & \multicolumn{4}{|c|}{ No. of leaves per plantlet } & \multicolumn{4}{|c|}{ No. of shoots formed per subculture } \\
\hline & & & & & & & & & & & & & \\
\hline NAA & $\mathbf{B A}$ & $\mathbf{A}$ & $\mathbf{F}$ & $\mathbf{C}$ & $\mathbf{L}$ & $\mathbf{A}$ & $\mathbf{F}$ & C & $\mathbf{L}$ & $\mathbf{A}$ & $\mathbf{F}$ & C & $\mathbf{L}$ \\
\hline 0 & 0 & 0 & 0 & 0 & 0 & 0 & 0 & 0 & 0 & 0 & 0 & 0 & 0 \\
\hline 0 & 3 & $2.1 \pm 0.3^{\mathrm{b}}$ & $1.7 \pm 0.2^{\mathrm{c}}$ & $1.3 \pm 0.1^{\mathrm{b}}$ & $1.6 \pm 0.1^{\mathrm{a}}$ & $3.2 \pm 0.3^{\mathrm{c}}$ & $3.3 \pm 0.2^{\mathrm{c}}$ & $2.2 \pm 0.1^{\mathrm{d}}$ & $3.0 \pm 0.2^{\mathrm{b}}$ & $3.2 \pm 0.4^{\mathrm{d}}$ & $11.0 \pm 1.5^{\mathrm{b}}$ & $2.2 \pm 0.1^{\mathrm{c}}$ & $1.0 \pm 0.1^{\mathrm{c}}$ \\
\hline 0 & 6 & $1.5 \pm 0.2^{\mathrm{d}}$ & $1.4 \pm 0.4^{\mathrm{d}}$ & $1.5 \pm 0.2^{\mathrm{b}}$ & $1.5 \pm 0.2^{\mathrm{b}}$ & $2.0 \pm 0.2^{\mathrm{d}}$ & $3.0 \pm 0.3^{\mathrm{c}}$ & $3.3 \pm 0.3^{\mathrm{c}}$ & $4.2 \pm 0.2^{\mathrm{a}}$ & $4.3 \pm 0.3^{\mathrm{d}}$ & $8.5 \pm 0.5^{\mathrm{d}}$ & $4.0 \pm 0.2^{\mathrm{b}}$ & $1.0 \pm 0.2^{\mathrm{c}}$ \\
\hline 0 & 9 & $1.6 \pm 0.3^{\mathrm{c}}$ & $1.2 \pm 0.3^{\mathrm{d}}$ & $1.3 \pm 0.1^{\mathrm{b}}$ & $1.4 \pm 0.2^{\mathrm{b}}$ & $3.1 \pm 0.3^{\mathrm{c}}$ & $2.5 \pm 0.3^{\mathrm{d}}$ & $3.0 \pm 0.2^{\mathrm{c}}$ & $3.2 \pm 0.1^{\mathrm{b}}$ & $8.5 \pm 0.5^{\mathrm{c}}$ & $6.5 \pm 0.5^{\mathrm{e}}$ & $5.0 \pm 0.2^{\mathrm{b}}$ & $1.0 \pm 0.1^{\mathrm{c}}$ \\
\hline 3 & 0 & $2.4 \pm 0.2^{\mathrm{b}}$ & $1.5 \pm 0.2^{\mathrm{d}}$ & $1.3 \pm 0.2^{\mathrm{b}}$ & $1.3 \pm 0.2$ & $3.2 \pm 0.1^{\mathrm{c}}$ & $4.2 \pm 0.4^{\mathrm{b}}$ & $3.0 \pm 0.2^{\mathrm{c}}$ & $3.3 \pm 0.2^{\mathrm{b}}$ & $2.0 \pm 0.3^{\mathrm{c}}$ & $8.0 \pm 0.7^{\mathrm{d}}$ & $2.0 \pm 0.1^{\mathrm{c}}$ & $1.0 \pm 0.2^{\mathrm{c}}$ \\
\hline 6 & 0 & $3.1 \pm 0.3^{\mathrm{a}}$ & $2.2 \pm 0.3^{\mathrm{b}}$ & $1.2 \pm 0.3^{\mathrm{b}}$ & $1.7 \pm 0.2^{\mathrm{a}}$ & $3.2 \pm 0.2^{\mathrm{c}}$ & $3.5 \pm 0.2^{\mathrm{c}}$ & $2.5 \pm 0.3^{\mathrm{d}}$ & $3.0 \pm 0.1^{\mathrm{b}}$ & $3.1 \pm 0.4^{\mathrm{d}}$ & $10.0 \pm 1.5^{\mathrm{c}}$ & $1.0 \pm 0.1^{\mathrm{d}}$ & $1.0 \pm 0.1^{\mathrm{c}}$ \\
\hline 9 & 0 & $1.1 \pm 0.2^{\mathrm{d}}$ & $1.1 \pm 0.3^{\mathrm{d}}$ & $1.0 \pm 0.1^{\mathrm{c}}$ & $1.2 \pm 0.1^{\mathrm{b}}$ & $2.0 \pm 0.1^{\mathrm{d}}$ & $2.4 \pm 0.1^{\mathrm{d}}$ & $2.2 \pm 0.1^{\mathrm{d}}$ & $2.5 \pm 0.2^{\mathrm{c}}$ & $2.0 \pm 0.2^{\mathrm{c}}$ & $6.5 \pm 1.0^{\mathrm{e}}$ & $1.0 \pm 0.2^{\mathrm{d}}$ & $1.0 \pm 0.2^{\mathrm{c}}$ \\
\hline 3 & 3 & $2.4 \pm 0.1^{\mathrm{b}}$ & $2.2 \pm 0.2^{\mathrm{b}}$ & $2.2 \pm 0.2^{\mathrm{a}}$ & $1.8 \pm 0.2^{\mathrm{a}}$ & $4.5 \pm 0.2^{\mathrm{a}}$ & $5.0 \pm 0.3^{\mathrm{b}}$ & $5.0 \pm 0.2^{\mathrm{b}}$ & $3.0 \pm 0.2^{\mathrm{b}}$ & $18.0 \pm 1.0^{\mathrm{a}}$ & $14.0 \pm 0.5^{\mathrm{a}}$ & $3.5 \pm 0.2^{\mathrm{c}}$ & $3.0 \pm 0.2^{\mathrm{a}}$ \\
\hline 3 & 6 & $1.9 \pm 0.4^{\mathrm{c}}$ & $1.5 \pm 0.2^{\mathrm{d}}$ & $1.2 \pm 0.3^{\mathrm{b}}$ & $1.2 \pm 0.1^{\mathrm{b}}$ & $3.0 \pm 0.3^{\mathrm{c}}$ & $3.0 \pm 0.4^{\mathrm{c}}$ & $6.0 \pm 0.3^{a}$ & $3.0 \pm 0.1^{\mathrm{b}}$ & $6.1 \pm 1.1^{\mathrm{c}}$ & $12.0 \pm 0.7^{\mathrm{b}}$ & $\mathbf{8 . 0} \pm 0.4^{\mathrm{a}}$ & $2.0 \pm 0.2^{\mathrm{b}}$ \\
\hline 3 & 9 & $1.8 \pm 0.2^{\mathrm{c}}$ & $1.4 \pm 0.3^{\mathrm{d}}$ & $1.2 \pm 0.2^{\mathrm{b}}$ & $1.2 \pm 0.1^{\mathrm{b}}$ & $2.1 \pm 0.1^{\mathrm{d}}$ & $3.0 \pm 0.2^{\mathrm{c}}$ & $3.0 \pm 0.2^{\mathrm{c}}$ & $2.5 \pm 0.1^{\mathrm{c}}$ & $3.1 \pm 0.5^{\mathrm{d}}$ & $5.0 \pm 0.5^{\mathrm{e}}$ & $2.0 \pm 0.2^{\mathrm{c}}$ & - \\
\hline 6 & 3 & $2.9 \pm 0.3^{\mathrm{a}}$ & $1.6 \pm 0.2^{\mathrm{c}}$ & $1.0 \pm 0.2^{\mathrm{c}}$ & $1.1 \pm 0.1^{\mathrm{b}}$ & $4.2 \pm 0.2^{\mathrm{b}}$ & $4.5 \pm 0.2^{b}$ & $3.0 \pm 0.1^{\mathrm{c}}$ & $2.5 \pm 0.1^{\mathrm{c}}$ & $9.2 \pm 1.5^{\mathrm{b}}$ & $12.0 \pm 1.0^{\mathrm{b}}$ & $5.0 \pm 0.3^{\mathrm{b}}$ & - \\
\hline 6 & 6 & $1.6 \pm 0.1^{\mathrm{c}}$ & $3.0 \pm 0.4^{\mathrm{a}}$ & $0.9 \pm 0.1^{\mathrm{c}}$ & $1.3 \pm 0.1^{\mathrm{b}}$ & $3.1 \pm 0.3^{\mathrm{c}}$ & $\mathbf{6 . 2} \pm 0.4^{\mathrm{a}}$ & $2.0 \pm 0.2^{\mathrm{d}}$ & $3.0 \pm 0.1^{\mathrm{b}}$ & $10.1 \pm 1.5^{\mathrm{b}}$ & $11.5 \pm 1.5^{\mathrm{b}}$ & $1.0 \pm 0.2^{\mathrm{d}}$ & - \\
\hline 6 & 9 & $1.9 \pm 0.1^{\mathrm{c}}$ & $2.5 \pm 0.2^{\mathrm{b}}$ & $1.1 \pm 0.3^{\mathrm{b}}$ & $1.0 \pm 0.1^{\mathrm{b}}$ & $3.1 \pm 0.3^{\mathrm{c}}$ & $3.0 \pm 0.2^{\mathrm{c}}$ & $2.0 \pm 0.1^{\mathrm{d}}$ & $2.0 \pm 0.1^{\mathrm{c}}$ & $8.5 \pm 1.0^{\mathrm{c}}$ & $9.0 \pm 0.5^{\mathrm{c}}$ & - & - \\
\hline 9 & 3 & $1.7 \pm 0.2^{\mathrm{c}}$ & $2.2 \pm 0.1^{\mathrm{b}}$ & $1.2 \pm 0.2^{\mathrm{b}}$ & - & $3.1 \pm 0.2^{\mathrm{c}}$ & $3.2 \pm 0.3^{\mathrm{c}}$ & $3.1 \pm 0.2^{\mathrm{c}}$ & $3.0 \pm 0.2^{\mathrm{b}}$ & $10.3 \pm 1.0^{\mathrm{b}}$ & $9.0 \pm 1.0^{\mathrm{c}}$ & - & - \\
\hline 9 & 6 & $2.1 \pm 0.3^{\mathrm{b}}$ & $2.0 \pm 0.3^{\mathrm{c}}$ & $1.1 \pm 0.2^{\mathrm{b}}$ & - & $3.1 \pm 0.2^{\mathrm{c}}$ & $3.0 \pm 0.2^{\mathrm{c}}$ & $2.5 \pm 0.2^{\mathrm{d}}$ & $3.0 \pm 0.1^{\mathrm{b}}$ & $3.0 \pm 0.5^{\mathrm{d}}$ & $5.5 \pm 0.6^{\mathrm{e}}$ & - & - \\
\hline 9 & 9 & $1.8 \pm 0.3^{\mathrm{c}}$ & $1.2 \pm 0.3^{\mathrm{d}}$ & - & - & $2.1 \pm 0.1^{\mathrm{d}}$ & $2.0 \pm 0.1^{\mathrm{d}}$ & $2.0 \pm 0.1^{\mathrm{d}}$ & $2.0 \pm 0.1^{\mathrm{c}}$ & $8.3 \pm 0.5^{\mathrm{c}}$ & - & - & - \\
\hline
\end{tabular}

In MS medium containing 3\% sucrose; Data represent the mean of five replicates; A: Agar gelling medium, $\mathbf{F}$ : Foam as substratum, $\mathbf{C}$ : Coconut coir as substratum, $\mathbf{L}$ : Forest litter as substratum; Standard error. In the same column, figures followed by the same letter were statistically identical to the threshold of $5 \%$. 

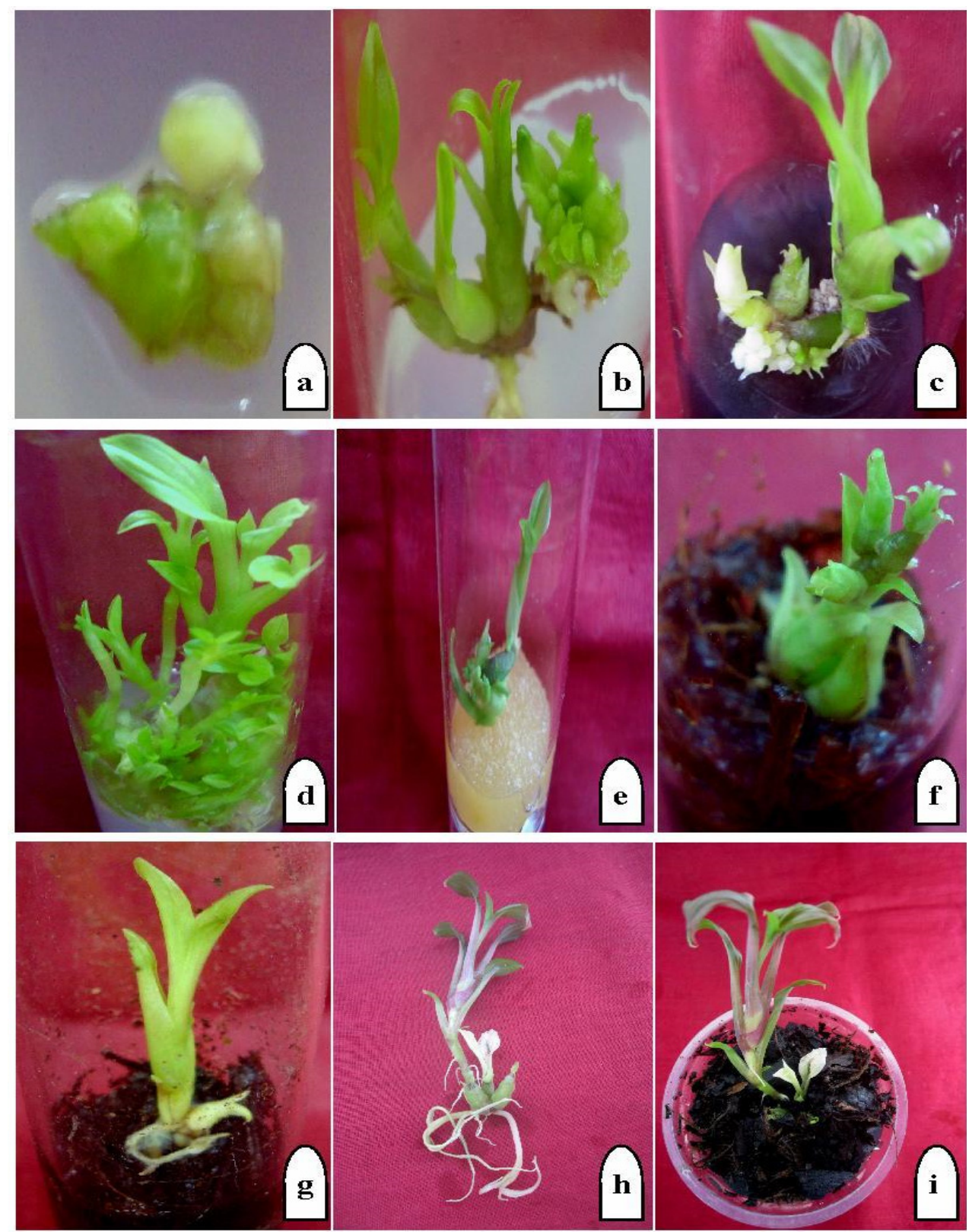

Figure 1. In vitro morphogenetic response of pseudobulb segments of Malaxis acuminata

a. Pseudobulb segment showing invocation of shoot buds, b. Multiple shoot buds/PLBs developed from the cultured pseudobulb segment, c. Multiple shoot buds/PLBs developed from the cultured pseudobulb segment on AC rich medium, d. Multiple plantlets formed on agar gelled medium, e. Plant regeneration of 'foam' as substratum, f. Multiple shoot buds developed on regeneration medium containing coconut coir as substratum, $g$ Plantlets on regeneration medium containing chopped forest litter as substratum, h. A well rooted hardened plant, i. A potted plant. 


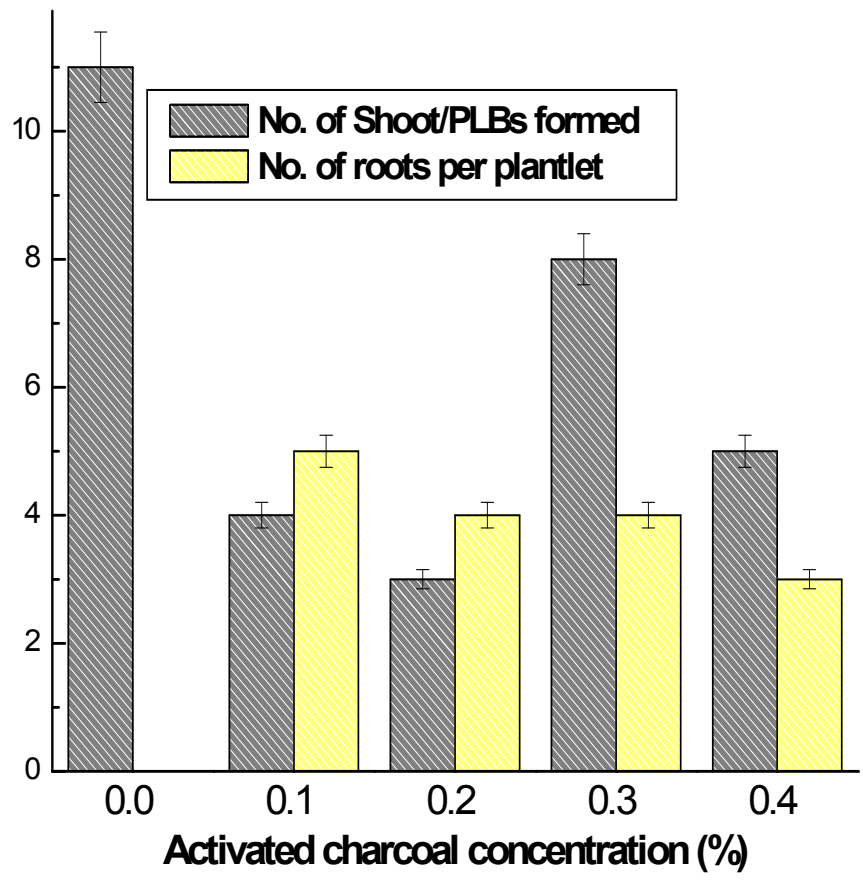

Figure 2. Effect of activated charcoal on in vitro morphogenetic induction of pseudobulb segments of Malaxis acuminata

\subsection{Hardening and Transplantation to Community Potting Mix}

The plantlets with 4-5 roots (Figure 1h) from regeneration medium were hardened for 7-8 wk as mentioned in materials and methods. The hardened plants were transferred to CPM and maintained in poly shade for two months before transferring to the wild (Figure 1i). About 75\% transplants survived after two months of transfer.

\section{Discussion}

In studies on pseudobulb culture of M. acuminata, regeneration competence of pseudobulb segments depend on the sources of the explants, types and position of the tissues used from donor explants, nutrient regime present in the culture medium. Though there was no meristematic loci invocation from the in vivo sourced pseudobulb segments except initial swelling at the cut ends, the in vitro sourced pseudobulb segments started swelling within 2-3 wk of culture initiation. In the present study shoot buds/PLBs formation was achieved from distal and proximal ends as well as from the leaf scars of the pseudobulbs. However, Vij and Dhiman (1997) reported morphogenetic response from pseudobulb segments of Bletilla striata irrespective of their position and orientation of segments. Perusal of literatures on regeneration competence of pseudobulb segments of orchids reveals that the positive results are mostly restricted with the in vitro sourced explants (Vij \& Pathak, 1989; Vij \& Dhiman, 1997; Sungkumlong \& Deb, 2009), but Sungkumlong and Deb (2009) could successfully establish cultures from pseudobulb segments of Taenia latifolia from both in vivo and in vitro sources.

For the present study different quality and quantity of PGRs and individual treatments of NAA and BA mostly supported PLBs formation. But when used in combination, supported shoots bud induction in $\sim 98 \%$ of cultured explants. The medium supplemented with $6 \mu \mathrm{M}$ each of NAA and BA in combination supported as many as 11 shoot buds/PLBs were formed after 70 days of culture initiation. At lower concentrations of combined treatments supported fewer shoot buds formation and fewer explants responded positively, while at higher concentrations (> $6 \mu \mathrm{M})$ cultures degenerated. In studies with Taenia latifolia pseudobulb segments, the cultures exhibited optimum response on MS medium fortified with NAA $(3 \mu \mathrm{M})$ and BA $(6 \mu \mathrm{M})$ in combination (Sungkumlong \& Deb, 2009). Pack et al. (1998); Sungkumlong and Deb (2009) and Deb and Sungkumlong (2010) observed that the requirements of exogenous supply of PGRs were species specific and it varied during initiation and multiplication stages. While, Peres et al. (1999) and Sungkumlong and Deb (2009), reported that the exogenous 
PGRs supply markedly influenced the morphogenic response by manipulating the endogenous level of auxin/cytokinin ratio. Present finding is in agreement with previous reports, where a synergistic action of auxin and cytokinin has been reported (Vij \& Agarwal, 2003; Deb \& Temjensangba, 2005; Sungkumlong \& Deb, 2009).

In general incorporation of $\mathrm{AC}$ in the initiation medium had no positive effect on shoot bud formation compared to $\mathrm{AC}$ control medium. But incorporation of $\mathrm{AC}$ in the initiation medium promoted healthy root formation and pigmentation in the plantlet and as many as 4-5 roots developed per shoot buds/plantlets which was lacking in $\mathrm{AC}$ control medium. Influence of AC on shoot induction has been documented in Coelogyne viscose (Vij et al., 1997); Malaxix khasiana (Deb \& Temjensangba, 2006); Taenia latifolia (Sungkumlong \& Deb, 2009).

The propagules developed from pseudobulb segments on initiation medium were cultured on regeneration medium for plant regeneration and culture proliferation. Of the different concentrations of PGRs, a combined treatment of NAA and BA at $3 \mu \mathrm{M}$ each supported healthy regeneration and culture proliferation. Earlier reports described that the change in culture conditions, medium and PGRs could alter the pattern of organogenesis in orchids and such behaviors can be judiciously explored for achieving optimal response in orchid species (Chen et al., 2004; Sungkumlong \& Deb, 2009; Deb \& Pongener, 2011; Pongener \& Deb, 2011).

In tissue culture the hunt for the cheaper alternative for agar could be that which is/are of very low cost and leads to lowering the production cost. In the past there were some efforts on use of different substrata as alternative to agar viz. agarose (Johanson, 1988), guar gum (Babbar et al., 2005), xanthan gum (Babbar \& Jain, 2006), forest leaf litters (Deb \& Imchen, 2010), foam, coconut coir, betel nut coir (Deb \& Pongener, 2010, 2011; Pongener \& Deb, 2011) with variable success as substitute of agar. In the present study the foam could be recycled for about 10-12 times, thereby reducing the production cost considerably. We could successfully use coconut coir, and foam as agar alternative for initiation and regeneration phase. Healthy plant regeneration, culture proliferation was accomplished on foam than other substrata.

In the present study we could reduce the production cost by about a fourth. The cost effectiveness of the present study compared to agar gelled medium is due to the fact that the agar gelled medium requires frequent sub-culture which many lead to undesired contamination and culture loss. But when alternative substrata are used, the nutrients in the culture vials could be recharged by simply pouring the fresh liquid medium in the culture vials and transfer the newly formed propagules in the new culture vials. This helps in minimizing the chances of contamination and manpower costs. Besides this, the substrata used in the present study are easily available as household wastes which are comparatively cheaper except foam.

According to our estimation in the present days market for One liter culture medium with tissue culture grade agar is $\sim 8.0$ US\$ and agar alone cost about $2.0 \mathrm{US} \$$. While foam required for one liter medium is $\sim 0.5$ US\$, which could be recycled up to 10-12 cycles. Therefore, the overall medium cost for 10 liters of medium with agar as gelling agent would be $\sim 80$ US\$ against $\sim 60.0$ US\$ only with foam thereby the production cost is reduced by about a fourth.

Besides this, most of the substrata used in the present study are eco-friendly as these are natural and renewable sources except 'foam' which is synthetic. If used in large scale for commercial purpose, the demand can be met without any fear of exploitation of its resources and also does not pose much threat to environment on being disposed as they are biodegradable. Further the regenerates on these substrata established themselves better on the CPM on potting compared to agar gelled medium as in most of the cases the roots of the regenerates adheres to the substratum as does by roots of orchids in their natural habitats.

\section{Conclusion}

The present study provide a newer route for clonal mass multiplication of Malaxis acuminata using pseudobulb segments as explants source whose population is down sized in the natural habitat. Outcome of the present study also offers a new route for using low cost substrata alternative to agar which will reduce production cost substantially.

\section{Acknowledgements}

Dr. T. Arenmongla is thankful to University Grant Commission, New Delhi, India for financial support through 'Rajiv Gandhi National Fellowship' for her Ph. D. work.

\section{References}

Arditti, J., \& Ernst, R. (1993). Micrppropagation of orchids. Jhon Wiley \& Sons., Inc., New York.

Arnold, S. V., \& Ericksson, T. (1984). Effect of agar concentration on growth and anatomy of adventitious shoot 
of Picea abies (L.) Karst. Plant Cell Tissue and Organ Culture, 3, 257-264. http://dx.doi.org/10.1007/BF00040345

Babbar, S. B., \& Jain. R. (2006). Xanthan gum: An economical partial substitute for agar in microbial culture media. Current Microbiology, 52, 287-292. http://dx.doi.org/10.1007/s00284-005-0225-5

Babbar, S. B., Jain, R., \& Walia, N. (2005). Guar gum as gelling agent for plant tissue culture media. In Vitro Cellular and Developmental Biology-Plant, 41, 258-261. http://dx.doi.org/10.1079/IVP2005628

Chauhan, N. S. (1990). Medicinal orchids of Himachal Pradesh. Journal of Orchid Society of India, 4, 99-103.

Chen, T. Y., Chen, J. T., \& Chang, W. C. (2004). Plant regeneration through direct shoot bud formation from leaf cultures of Paphiopedilum orchids. Plant Cell Tissue and Organ Culture, 76, 11-15. http://dx.doi.org/10.1023/A:1025858211320

Deb, C. R., \& Imchen, T. (2010). An efficient in vitro hardening technique of tissue culture raised plants. Biotechnology, 9(1), 79-83. http://dx.doi.org/10.3923/biotech.2010.79.83

Deb, C. R., \& Pongener, A. (2010). Search of alternative substratum for agar in plant tissue culture. Current Science, 98, 99-102.

Deb, C. R., \& Pongener, A. (2011). Asymbiotic seed germination and in vitro seedling development of Cymbidium aloifolium (L.) Sw.: a multipurpose orchid. Journal of Plant Biochemistry and Biotechnology, 20(1), 90-95. http://dx.doi.org/10.1007/s13562-010-0031-4

Deb, C. R., \& Sungkumlong. (2010). Regenerative competence of foliar explants of Coelogyne suaveolens and Taenia latifolia: two threatened orchids of North-East India. Applied Biological Research, 12, 1-9.

Deb, C. R., \& Temjensangba. (2005). In vitro regenerative competence of Cleisostoma racemiferum (Orchidaceae) aerial roots. Journal of Plant Biochemistry and Biotechnology, 14, 201-204. http://dx.doi.org/10.1007/BF03263247

Deb, C. R., \& Temjensangba. (2006). In vitro propagation of threatened terrestrial orchid, Malaxis khasiana Soland ex. Swartz through immature seed culture. Indian Journal of Experimental Biology, 44, 762-766.

Deb, C. R., Deb, M. S., Jamir, N. S., \& Imchen, T. (2009). Orchids in indigenous system of medicine in Nagaland, India. Pleione, 3, 209-211.

Johanson, L. B. (1988). Increased induction of embryogenesis and regeneration in anther cultures of Solanum tuberosum L. Potato Research, 31, 145-149. http://dx.doi.org/10.1007/BF02360031

Murashige, T., \& Skoog, F. (1962). A revised medium for rapid growth and bioassays with tobacco tissue culture. Plant Physiology, 15, 473-497. http://dx.doi.org/10.1111/j.1399-3054.1962.tb08052.x

Pack, K. Y., Kozai, T., \& Pack, K. Y. (1998). Micropropagation of temperate Cymbidium via rhizome culture. Horticultural Technology, 8, 283-288.

Pareek, A., \& Kothari, S. L. (2002). Adventitious shoot regeneration from leaf explants in ornamental species Dianthus. Journal of Indian Botanical Society, 81: 339-342.

Peres, L. E. P., Amar, S., Kerbauy, G. B., Salatino, A., Zaffari, A. R., \& Mereier, H. (1999). Effect of auxin, cytokinin and ethylene treatments on the endogenous ethylene and auxin to cytokinins ratio related to direct root tip conversion of Catasetum fimbriatum Lindl. (Orchidaceae) into buds. Journal of Plant Physiology, 155, 551-555. http://dx.doi.org/10.1016/S0176-1617(99)80053-4

Pongener, A., \& Deb, C. R. (2011). In vitro regeneration of plantlets of Cymbidium iridioides D. Don using nodal segments as explants. International Journal of Applied Biotechnology and Biochemistry, 1(4), 389-400.

Sungkumlong, \& Deb, C. R. (2009). Regenerative competence of Taenia latifolia (Lindl.) Benth ex. Hook pseudobulb segments: an in vitro study. Indian Journal of Biotechnology, 8, 121-126.

Temjensangba, \& Deb, C. R. (2005). Regeneration of plantlets from in vitro raised leaf explants of Cleisostoma racemiferum Lindl. Indian Journal of Experimental Biology, 43, 377-381.

Vij, S. P., \& Aggarwal, S. (2003). Regenerative competence of foliar explants: Vanda coerulea Griff. Journal of Orchid Society of India, 17, 73-78.

Vij, S. P., \& Dhiman, A. (1997). Regenerative competence of Bletilla striata pseudobulbs segments: a study in vitro. Journal of Orchid Society of India, 11, 93-97.

Vij, S. P., \& Pathak, P. (1989). Micropropagation of Dendrobium chrysanthum Wall. through pseudobulb 
segments. Journal of Orchid Society of India, 3, 25-28.

Vij, S. P., Kher, A. \& Pathak, P. (2000). Regenerative competence of Bulbophyllum careyanum (Hook.) Spreng. pseudobulb segments. Journal of Orchid Society of India, 14, 47-55.

Vij, S. P., Pathak, P., \& Mahant, K. C. (1997). On the regenerative competence of Coelogyne viscose pseudobulb explants. In Proceedings of the 5th National Seminar on Developmental Biology and Commercialization of Orchid, pp. 88-92. The Orchid Society of India, Chandigarh, India.

\section{Copyrights}

Copyright for this article is retained by the author(s), with first publication rights granted to the journal.

This is an open-access article distributed under the terms and conditions of the Creative Commons Attribution license (http://creativecommons.org/licenses/by/3.0/). 